\title{
Effects of shrub species and microhabitats on dew formation in a revegetation-stabilized desert ecosystem in Shapotou, northern China
}

\author{
YanXia PAN, XinPing WANG* \\ Shapotou Desert Experimental Research Station, Cold and Arid Regions Environmental and Engineering Research Institute, \\ Chinese Academy of Sciences, Lanzhou 730000, China
}

\begin{abstract}
Dew is an important supplement water source in arid and semi-arid areas. In order to determine the dew formation on different kinds of soils associated with various shrub species and microhabitats, we performed measurement of accumulated dew formation amount and duration in October 2009 in a revegetation-stabilized arid desert ecosystem in Shapotou area, northern China. The results indicated that the accumulated dew formation amount was four times larger at open spaces as compared to under the canopy, and it was nearly twice as much under living Artemisia ordosica plants (L.A.) as compared to under living Caragana korshinskii plants (L.C.). The opposite characteristics were found for dew duration between different microhabitats. Dew amounts at different vertical heights around the shrub stands were in the order of $50 \mathrm{~cm}$ above the canopy>the canopy edge>under the canopy. Dew amount continued to increase after dawn, and the proportion of average accumulated dew amount after dawn accounting for the average maximum amount increased from above the canopy to under the canopy. Dew formation duration after sunrise accounted for more than $50 \%$ of the total formation duration during the day time. Contrary to the distribution characteristics of dew amount, dew duration after dawn and total dew formation duration during the day time were both highest under the canopy, followed by at the canopy edge and then at $50 \mathrm{~cm}$ above the canopy. The portion of dew duration after dawn accounting for the total dew duration during the day time increased from above the canopy to under the canopy. From these results, we may conclude that dew availability as a supplemental water resource for improving the microhabitats in water-limited arid ecosystems is position dependent especially for the plant microhabitats at different stands layers.
\end{abstract}

Keywords: dew amount; dew duration; shrub species; microhabitat; soil surface type

Citation: YanXia PAN, XinPing WANG. 2014. Effects of shrub species and microhabitats on dew formation in a revegetation-stabilized desert ecosystem in Shapotou, northern China. Journal of Arid Land, 6(4): 389-399. doi: 10.1007/s40333-014-0008-6

An important component of micro-hydrology in arid regions is the input of non-rainfall atmospheric moisture via dew (Kosmas et al., 1998; Agam and Berliner, 2006; Brown et al., 2008). Dew is an important usable water resource in desert environments with scarce water, where dew can efficiently reduce water loss caused by soil evaporation and is crucial to maintaining water balance, especially over large time scales (Lekouch et al., 2011; Hao et al., 2012). Dew is also beneficial to the growth and development of biological soil crusts (Agam and Berliner, 2002; Pan et al., 2010).
Moreover, some plants can directly absorb the dew that forms on the canopy surface through their leaves, thereby alleviating water deficit (Jacobs et al., 2000; Zheng et al., 2011; Zhuang and Ratcliffe, 2012), extending life period, improving flowering and fruit quantity, promoting growth and increasing above- or below-ground biomass (Martin and Willert, 2000; Gouvra and Grammatikopoulos, 2003; Breshears et al., 2008; Simonin et al., 2009). In the semi-arid regions of Chile, forests are largely dependent on the deposition of fog water (Del-Val et al., 2006). Dew is also an

*Corresponding author: XinPing WANG (E-mail: xpwang@lzb.ac.cn) Received 2013-11-16; revised 2014-01-10; accepted 2014-02-23

(C) Xinjiang Institute of Ecology and Geography, Chinese Academy of Sciences, Science Press and Springer-Verlag Berlin Heidelberg 2014 
important water resource for the survival of animals in arid areas (Moffett, 1985; Shachak et al., 2002). Due to the water resources from dew, animals, plants and microorganisms can survive in arid and semi-arid environments, making the ecosystems full of vitality. Dew can influence the energy balance of soil-vegetation-atmosphere interface that can be the main sink of available energy in the morning (Pitacco et al., 1992), and impact the air temperature around the vegetation canopy (Bourque and Arp, 1994). Therefore, the effect of dew should be considered when analyzing the energy exchange processes within the shrub canopy (Jacobs et al., 1996).

Dew formation is a complex physical process, and numerous meteorological factors control the duration and amount of dew (Ye et al., 2007; Wang and Zhang, 2011). Moreover, soil characteristics, topography, water resource condition, underground water depth, snow accumulation, frozen crust and other factors also influence dew formation (Li, 2002; Kidron, 2005; Ye et al., 2007; Pan et al., 2010). The distribution of branches and leaves at a certain height induces the change of heat flux within the vegetation canopy, subsequently influences dew formation and results in a complex distribution of dew. The distribution characteristics of leaves change along with the growth and development of plants (Mao et al., 2012), and consequently the vegetation type and development stage all influence the formation of dew (Xiao et al., 2009). In the Shapotou area, Caragana korshinskii and Artemisia ordosica were the primary shrubs used for artificial revegetation at the early stage. However, during more than 50 years of evolutionary process, a large number of cryptogam and annual herbage colonized and multiplied here, changing the distribution characteristics of soil moisture, resulting in the death of a great quantity of shrub species and producing different shrub populations. Although some progress has been made on researching dew formation, the characteristics of dew formation under different microhabitats and the vertical variation of dew formation around the same shrub species in the Shapotou area have not been studied.

In this study, we assumed that the change of microhabitats could induce a variation of dew formation characteristics. Two typical artificial shrub species with different development stages together with bare sand dunes were chosen to evaluate the possible effects of microhabitats on dew formation. The aims of this study were as follows: (1) the influences of shrub species and microhabitats on the formation characteristics of accumulated dew amounts and duration for different kinds of soils; and (2) the vertical distribution characteristics of accumulated dew amounts and duration around different shrub species for different kinds of soils. The research will promote the understanding of dew formation characteristics under different microhabitats and soil characteristics (i.e. different soil evolution stages), and the significance of dew in combating desertification and promoting vegetation restoration.

\section{Materials and methods}

\subsection{Study area}

The experiment was carried out in the desert steppe region $\left(37^{\circ} 32^{\prime} \mathrm{N}, 105^{\circ} 02^{\prime} \mathrm{E} ; 1,288 \mathrm{~m}\right.$ asl) at the Shapotou Desert Experimental Research Station, Chinese Academy of Sciences, bordering the Tengger Desert. According to the meteorological records between 1955 and 2005, the annual mean temperature is $10.6^{\circ} \mathrm{C}$, with a minimum monthly mean temperature of $-6.3^{\circ} \mathrm{C}$ in January and a maximum of $24.9^{\circ} \mathrm{C}$ in July. The mean annual precipitation is $193 \mathrm{~mm}$, most of which are received during the monsoon period between May and September (Pan and Wang, 2009). The mean annual potential evaporation is approximately $3,000 \mathrm{~mm}$. The growing period ranges from 150 to 180 days per year. The predominant species are $\mathrm{He}$ dysarum scoparium and Agriophyllum squarrosum with a cover of approximately 1\%-2\% (Shapotou Desert Experimental Research Station, Chinese Academy of Sciences, 1991). The soil is classified as orthic sierozem and eolian sandy soil (Li et al., 2007). The spatial heterogeneity of the study area is characterized by patches of perennial shrubs, and the originally artificially revegetated shrubs $C$. korshinskii and A. ordosica formed different landscape types along with the death of shrubs.

\subsection{Experimental design and data collection}

A dew measurement program was carried out in a soil water balance experimental field that was revegetated in 1989 at Shapotou in October 2009. Five distinctively different microhabitats, including bare sand dunes fixed by straw-checkerboards without plants, 
the inter-space of $C$. korshinskii plants (I.C.), living $C$. korshinskii plants (L.C.), dead C. korshinskii plants (D.C.) and living A. ordosica plants (L.A.), were chosen for dew measurement. The Sartorius CPA34001S balance, covered by quartz glass containers filled with biological soil crusts, was installed under the canopy of L.C. during the whole measurement period, and under different microhabitats for different measurements. Cylindrical PVC containers filled with three different soil columns (bare dune sand, physical soil crusts and biological soil crusts) were placed at the same location within the five different microhabitats from 17 to 24 October 2009. For determining the vertical variation characteristics of dew formation around the shrubs, cylindrical PVC containers filled with three different soil columns were placed under the canopy, at the canopy edge and at $50 \mathrm{~cm}$ above the canopy using stainless steel pillars around the living I.C. and L.A. Three replicate measurements were carried out for each microhabitat. Eighty-one cylindrical PVC containers were used in all. The detailed measurement methods and data collection were described in Pan et al. (2010). The surface air temperature, relative humidity and wind speed at $2 \mathrm{~m}$ above the soil surface were measured using an auto weather station (WS-STD1, Britain) within the measurement field.

\subsection{Statistical analyses}

All statistical analyses were conducted using Origin 8.0 and SPSS 12.0 package (SPSS 12.0 Inc., Chicago, USA). The differences in accumulated dew amounts and duration for different microhabitats were quantified using analysis of variance (ANOVA). The statistically significant difference for all analyses was set at $P<0.01$ and $P<0.05$.

\section{Results}

\subsection{Dew diurnal formation characteristics for different microhabitats}

The diurnal formation characteristics of dew for I.C. and L.C. (Fig. 1a) indicated that the accumulated dew amount increased gradually from 19:00 to 06:00, although the relative humidity was not saturated and the air temperature was higher than the dew point at this time. From 06:00 to 08:00, the relative humidity was saturated, the air temperature was equal to or lower than the dew point, and the accumulated dew amount increased rapidly. These results demonstrated that the increase of accumulated dew amount during a day can be divided into two stages: the first stage was the water absorption process that began after 18:00 when the soil moisture content reduced to a minimum, and the other occurred during the condensation process when the air temperature was lower than the dew point and the relative humidity was saturated before 06:00. These two processes favoured the increase of soil moisture by dew formation. The formation period of dew occurred from 18:00 on the previous day to 08:00-09:00 during the next day for the two microhabitats. Then, the air temperature rose after 09:00, while the accumulated dew amount decreased gradually after reaching a maximum, indicating that water vapour absorption and condensation process happened on the surface soils for both I.C. and L.C. at night consisting partly of coincident dew loss by evaporation. The beginning time of dew formation was nearly synchronous for I.C. and L.C. The meteorological condition was the key factor triggering this formation process. When the air temperature began to decrease, the relative humidity began to increase. At the same time, the wind force also weakened gradually from a stronger afternoon wind at 18:00 to a gentle breeze favouring dew formation. The variation amplitude of accumulated dew amount at night was nearly three times larger for I.C. than for L.C., and the alternation of evaporation and condensation was obvious for I.C. at 08:00. The corresponding meteorological data indicated that the effect of wind on accumulated dew amount was distinct for I.C., and the water vapour delivery effect of gentle breeze accelerated the dew formation. The accumulated dew amount for I.C. achieved the maximum value at approximately 08:00, and then it evaporated gradually due to the increase of solar radiation. Dew formation was lagged for L.C. compared to I.C., because the maximum accumulated dew formation amount appeared at 10:00 and was less significant $(P>0.01)$ for L.C. The maximum accumulated dew amounts were 0.86 and $0.31 \mathrm{~mm}$ for I.C. and L.C., respectively. The microhabitats formed by the shrub stands delayed the favorable time of outside meteorological condition in the canopy, and the vegetation itself partially intercepted the atmosphere input water and then decreased the water arriving on the ground. The shelter from the shrub stands weakened 

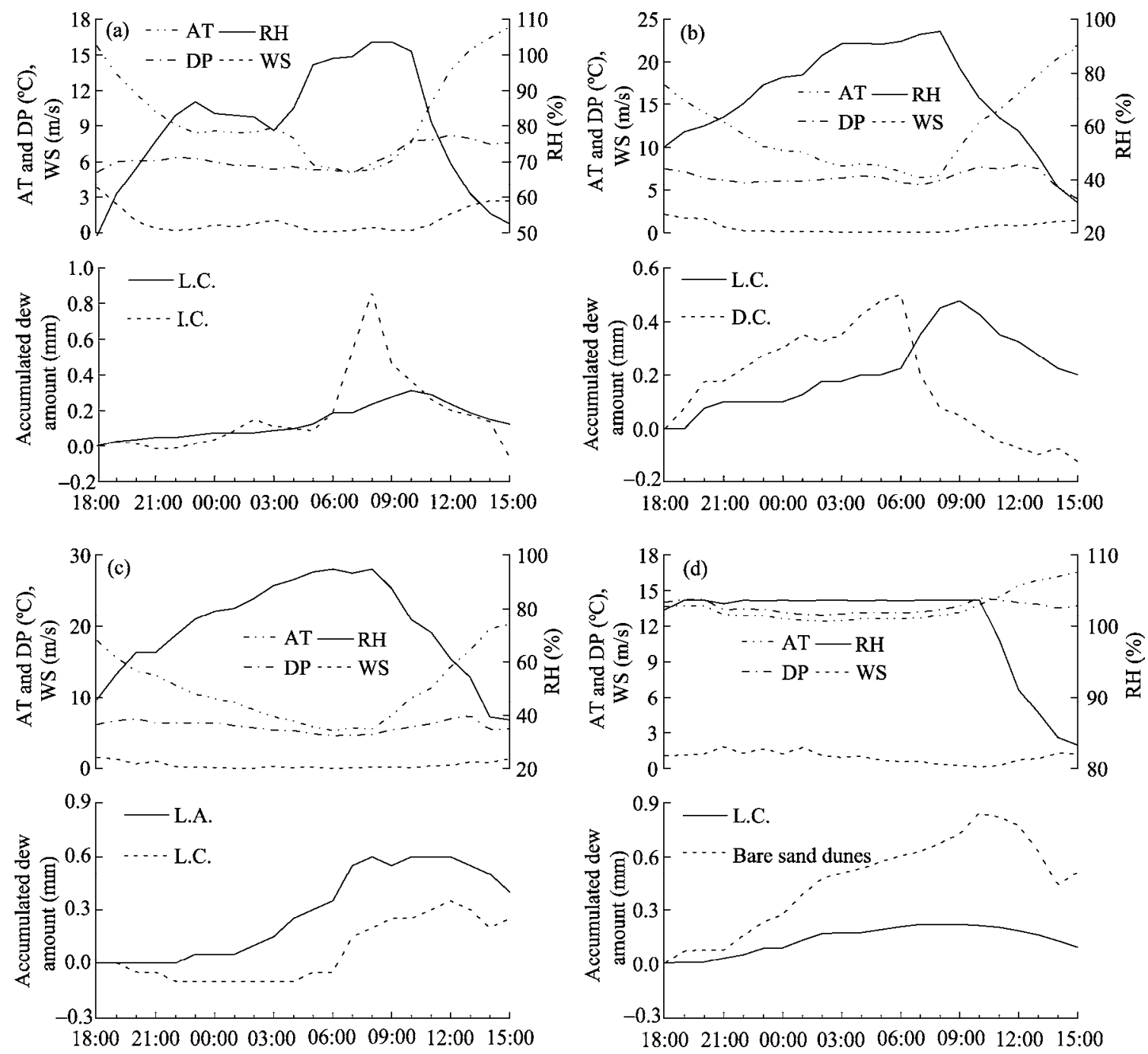

Fig. 1 Dew formation characteristics on biological soil crusts for different microhabitats and the corresponding meteorological data. The meteorological data were given at the same time with the accumulated dew amounts. (a), 4-5 October 2009; (b), 5-6 October 2009; (c), 6-7 October 2009; (d), 7-8 October 2009. AT, air temperature; DP, dew point; RH, relative humidity; WS, wind speed. L.C., living C. korshinskii plants; I.C., the inter-space of C. korshinskii plants; D.C., dead C. korshinskii plants; L.A., living A. ordosica plants.

the soil evaporation and delayed the dew loss process for L.C.

The formation characteristics of dew for L.C. and D.C. at the measurement date (Fig. 1b) indicated that the increase of accumulated dew amount resulted from the water vapour absorption because the air temperature was higher than the dew point for the duration of the observation. The maximum accumulated dew formation amount was similar for L.C. and D.C., at 0.48 and $0.50 \mathrm{~mm}$, respectively, and the appearance time of the maximum accumulated dew amount was 3 hours later for L.C. than for D.C. The accumulated dew formation amount was always larger for D.C. than for L.C. at night, and the difference increased gradually until they attained the maximum values. The accumulated dew amount for D.C. decreased rapidly after reaching a maximum. For L.C., the accumulated dew amount reached a maximum until approximately 09:00, undergoing a slow evaporation process due to the shelter of the shrub stands, and the increased dew amount at night was consumed entirely by evaporation at approximately 10:00.

For the preceding night of dew formation, the accumulated dew amount increased linearly from 18:00 to $06: 00-09: 00$ and arrived at a maximum. The water then evaporated gradually due to solar radiation, and the minimum appeared between 16:00 and 18:00, with a nearly linear decrease process despite occurring at a 
greater speed than the previous evaporation process.

The dew formation characteristics for L.C. and L.A. (Fig. 1c) indicated that the accumulated dew amount arrived at a maximum before 08:00 for both L.C. and L.A. The variation characteristics of meteorological factors indicated that the relative humidity was higher and reached a maximum at 07:00 with the value of nearly $100 \%$. Adequate water in the air was a key factor for the maximum accumulated dew amount. The accumulated dew formation amount was always less for L.C. than for L.A., and a stable evaporation process was observed even at night. The maximum accumulated dew amounts were 0.35 and $0.60 \mathrm{~mm}$ for L.C. and L.A., respectively. Compared to A. ordosica plants, the larger canopy of C. korshinskii plants intercepted more water vapour and formed closed microhabitats, resulting in lower accumulated dew amount and delaying the formation beginning time. The evaporation process of dew after 08:00 was relatively stable for the two microhabitats, while the decrease of soil moisture was slower for L.C. than for L.A. The more dense canopy of $C$. korshinskii plants hindered the absorption and condensation of water vapour, and then slowed the subsequent evaporation process.

The accumulated dew amounts under the same meteorological condition were greatly different $(P<0.01)$ for L.C. and bare sand dunes (Fig. 1d). From 19:00 on the observation date, the relative humidity was nearly saturated and the air temperature was lower than the dew point. The water vapour condensed on the soil surface for the entire observation period, and the soil moisture increased continuously and reached a maximum at approximately 10:00 for the two microhabitats. The maximum accumulated dew formation amounts were 0.22 and $0.84 \mathrm{~mm}$ for L.C. and bare sand dunes, respectively, and the increasing trend was slower for L.C. than for bare sand dunes. More water vapour was intercepted by the C. korshinskii stands, so it could not condense on the surface soil under the plants. Due to increased solar radiation after 10:00, the relative humidity reduced, the air temperature increased rapidly, the evaporation process of soil surface moisture began, and the decrease of soil moisture was slower for L.C. than for bare sand dunes. Further, the condensation and evaporation processes were symmetrical to each other on the bare sand dunes.

\subsection{Vertical distribution characteristics of dew around the shrub stands}

The accumulated dew amounts on three kinds of soils at different vertical heights around the $C$. korshinskii and A. ordosica plants (Figs. 2 and 3) indicated that the accumulated dew amount at $50 \mathrm{~cm}$ above the canopy was greater, followed by at the canopy edge and then under the canopy. The mean accumulated dew amounts were 4.6, 4.3 and $3.6 \mathrm{~mm}$ at $50 \mathrm{~cm}$ above the canopy, at the canopy edge and under the canopy around the $C$. korshinskii plants for three kinds of soils, respectively; whereas the values were $0.7,0.6$ and $0.5 \mathrm{~mm}$ around the A. ordosica plants, respectively. The results of ANOVA indicated that the accumulated dew amounts around the C. korshinskii and A. ordosica plants for the same soil and height were not significantly different $(P=0.25)$. The mean accumulated dew amounts on biological soil crusts were 0.82 , 0.78 and $0.62 \mathrm{~mm}$ for $50 \mathrm{~cm}$ above the canopy, at the canopy edge and under the canopy around the $C$. korshinskii plants, respectively, and no significant difference $(P=0.17)$ was found for the three vertical heights. Meanwhile, the mean accumulated dew amounts at 50 $\mathrm{cm}$ above the canopy, at the canopy edge and under the canopy were $0.54,0.49$ and $0.43 \mathrm{~mm}$ on physical soil crusts, respectively, and $0.37,0.33$ and $0.30 \mathrm{~mm}$ on bare sand dunes, respectively. Similarly, no significant difference $(P=0.16)$ was found for the three vertical heights (Fig. 2). For the same vertical height, the accumulated dew amount on biological soil crusts was significantly greater $(P<0.01)$ than that on physical soil crusts and bare sand dunes, and no significant difference $(P=0.09)$ was found for the physical soil crusts and the bare sand dunes (Fig. 2). The results were the same around the A. ordosica plants (Fig. 3).

The accumulated dew amounts were 0.82 and 0.79 $\mathrm{mm}$ at $50 \mathrm{~cm}$ above the canopy around the $C$. korshinskii and A. ordosica plants, respectively (Fig. 4). For the two kinds of shrubs, the accumulated dew amounts were 0.78 and $0.71 \mathrm{~mm}$ at the canopy edge, respectively, and 0.62 and $0.73 \mathrm{~mm}$ under the canopy, respectively. The mean accumulated dew amounts were the same $(0.74 \mathrm{~mm})$ around the C. korshinskii and A. ordosica plants for different vertical heights (Fig. 4).

We determined the average maximum accumulated dew amount based on the time that the average dew amounts under different microhabitats reached the 

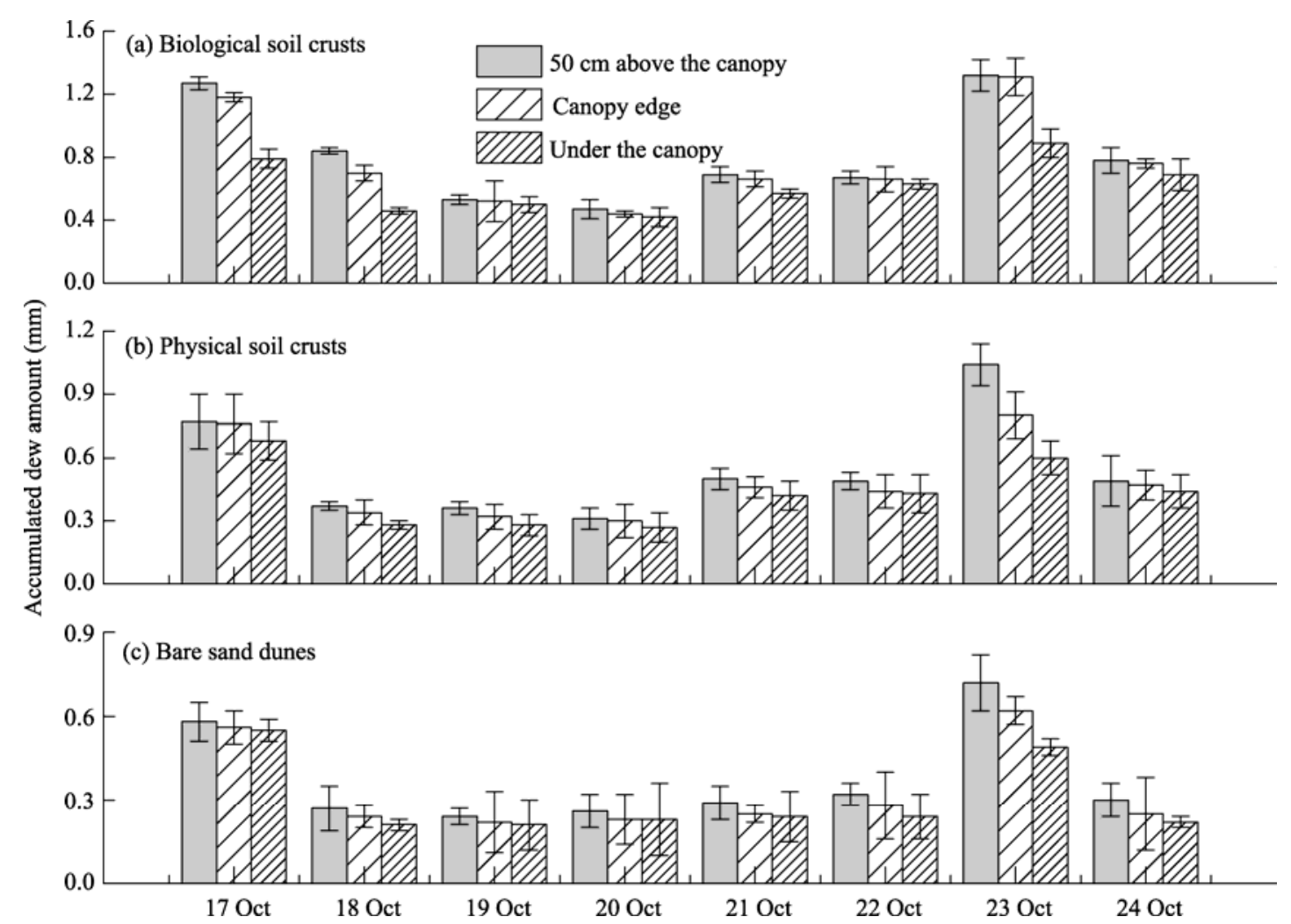

Fig. 2 Vertical variation of accumulated dew amounts around the C. korshinskii plants on biological soil crusts (a), physical soil crusts (b) and bare sand dunes (c) in October 2009. Bars represent one standard error, $n=3$.
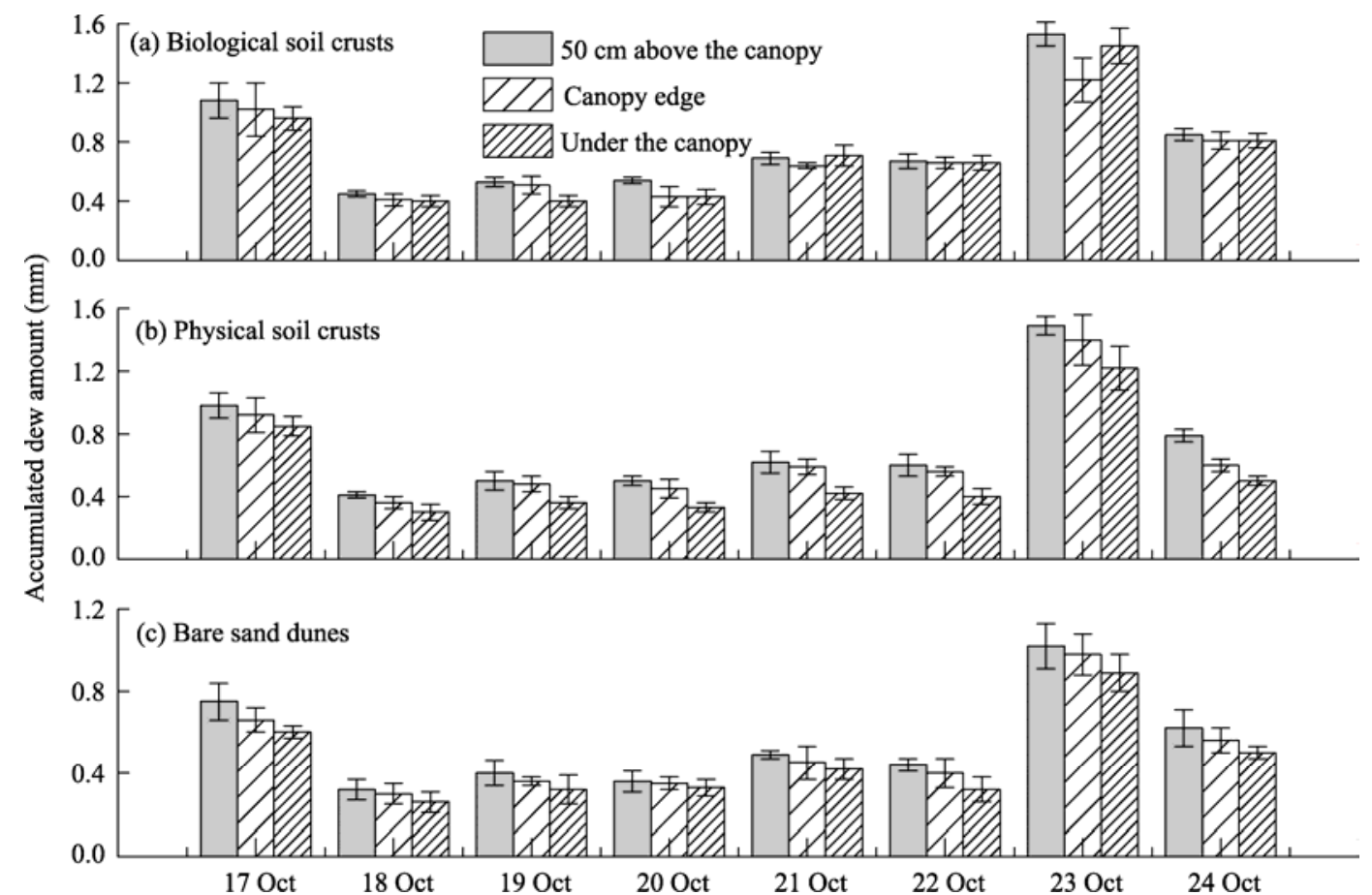

Fig. 3 Vertical variation of accumulated dew amounts around the $A$. ordosica plants on biological soil crusts (a), physical soil crusts (b) and bare sand dunes (c) in October 2009. Bars represent one standard error, $n=3$. 


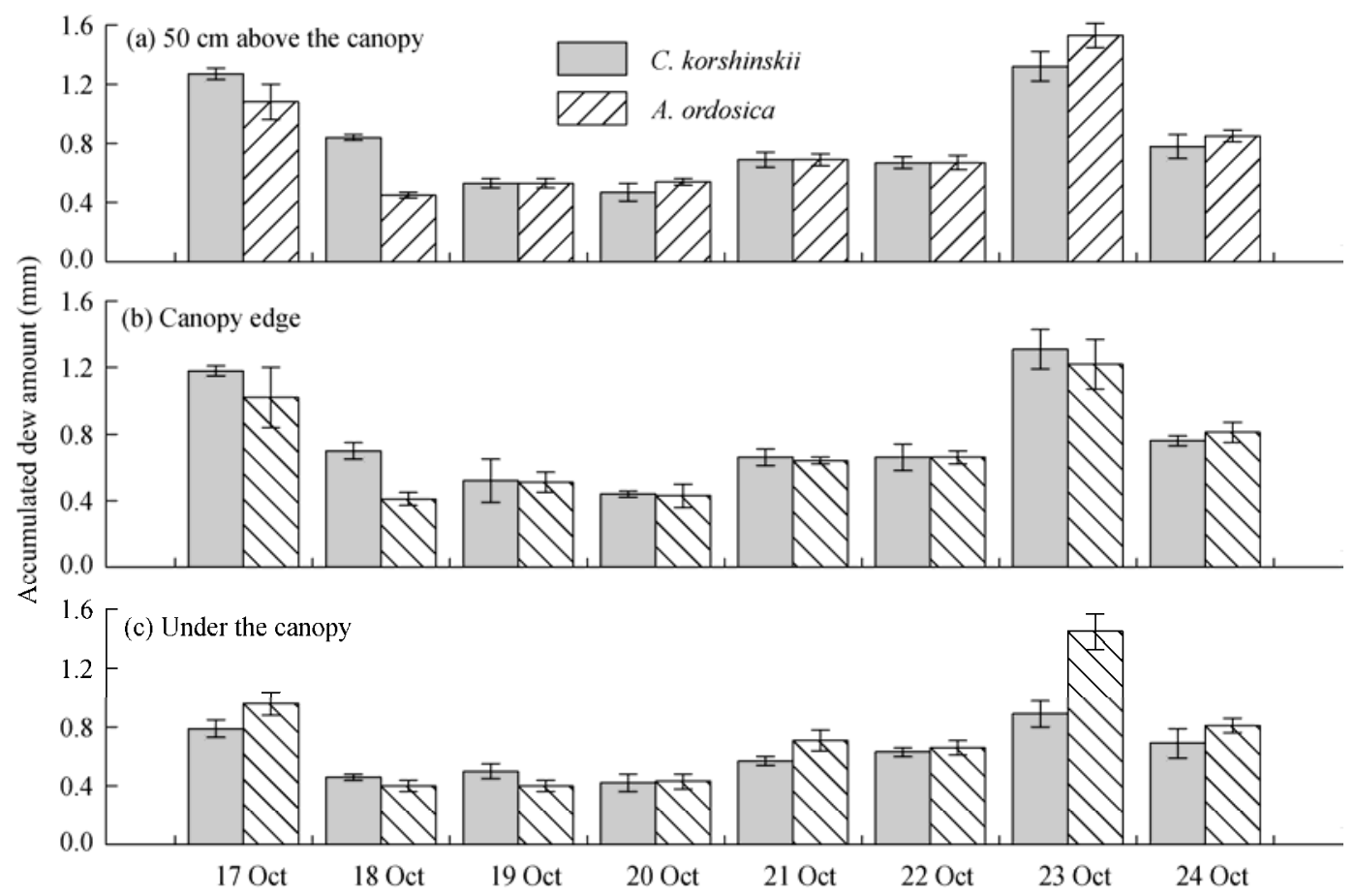

Fig. 4 Accumulated dew amounts at different vertical heights around the C. korshinskii and A. ordosica plants on biological soil crusts. Bars represent one standard error, $n=3$.

maximum. Evaporation process had begun under some microhabitats before the average maximum accumulated dew amount occurred. There was no significant difference $(P=0.25)$ for the average accumulated dew amounts at dawn and the average maximum accumulated dew amounts around the $C$. korshinskii and A. ordosica plants (Fig. 5). The average accumulated dew amounts after dawn on biological soil crusts accounted for $7.7 \%, 11.0 \%$ and $18.9 \%$ of the average maximum accumulated dew amounts at $50 \mathrm{~cm}$ above the canopy, at the canopy edge and under the canopy around the C. korshinskii plants, respectively. The proportions were $7.7 \%, 10.8 \%$ and $17.7 \%$ at this three vertical heights on physical soil crusts, respectively, and $6.3 \%, 11.2 \%$ and $19.0 \%$ on bare sand dunes, respectively. For the A. ordosica plants, the average accumulated dew amounts after dawn on biological soil crusts accounted for $9.8 \%, 13.4 \%$ and $20.3 \%$ of the average maximum values at $50 \mathrm{~cm}$ above the canopy, at the canopy edge and under the canopy, respectively. The proportions were $8.9 \%, 14.2 \%$ and $20.8 \%$ at this three vertical heights on physical soil crusts, respectively, and $8.9 \%, 13.4 \%$ and $20.4 \%$ on bare sand dunes, respectively. The formation of dew after dawn was a normal phenomenon at different vertical heights around the C. korshinskii and A. ordosica plants, and the proportion of average accumulated dew amount at dawn accounting for the average maximum value was larger under the canopy compared to the other two heights.

A significant difference was found for the time lapse between dawn and maximum dew and the daylight dew duration time on three kinds of soils at three vertical heights around the $C$. korshinskii and A. ordosica plants (Fig. 6). The time lapses between dawn and maximum dew on biological soil crusts accounted for $51.5 \%, 61.0 \%$ and $71.4 \%$ of the daylight dew duration time at $50 \mathrm{~cm}$ above the canopy, at the canopy edge and under the canopy around the $C$. korshinskii plants, respectively. The proportions were $51.5 \%$, $56.8 \%$ and $67.4 \%$ at this three vertical heights on physical soil crusts, respectively, and 51.5\%, 52.9\% and $64.4 \%$ on bare sand dunes, respectively. However, for the A. ordosica plants, the time lapses between dawn and maximum dew on biological soil crusts accounted for $56.8 \%, 66.0 \%$ and $70.9 \%$ of the daylight dew duration time at $50 \mathrm{~cm}$ above the canopy, at the canopy edge and under the canopy respectively. The proportions were $51.5 \%, 67.4 \%$ and $69.8 \%$ on physical soil crusts, and $51.5 \%, 55.6 \%$ and $61.9 \%$ on bare sand dunes, respectively. Dew duration after sunrise 


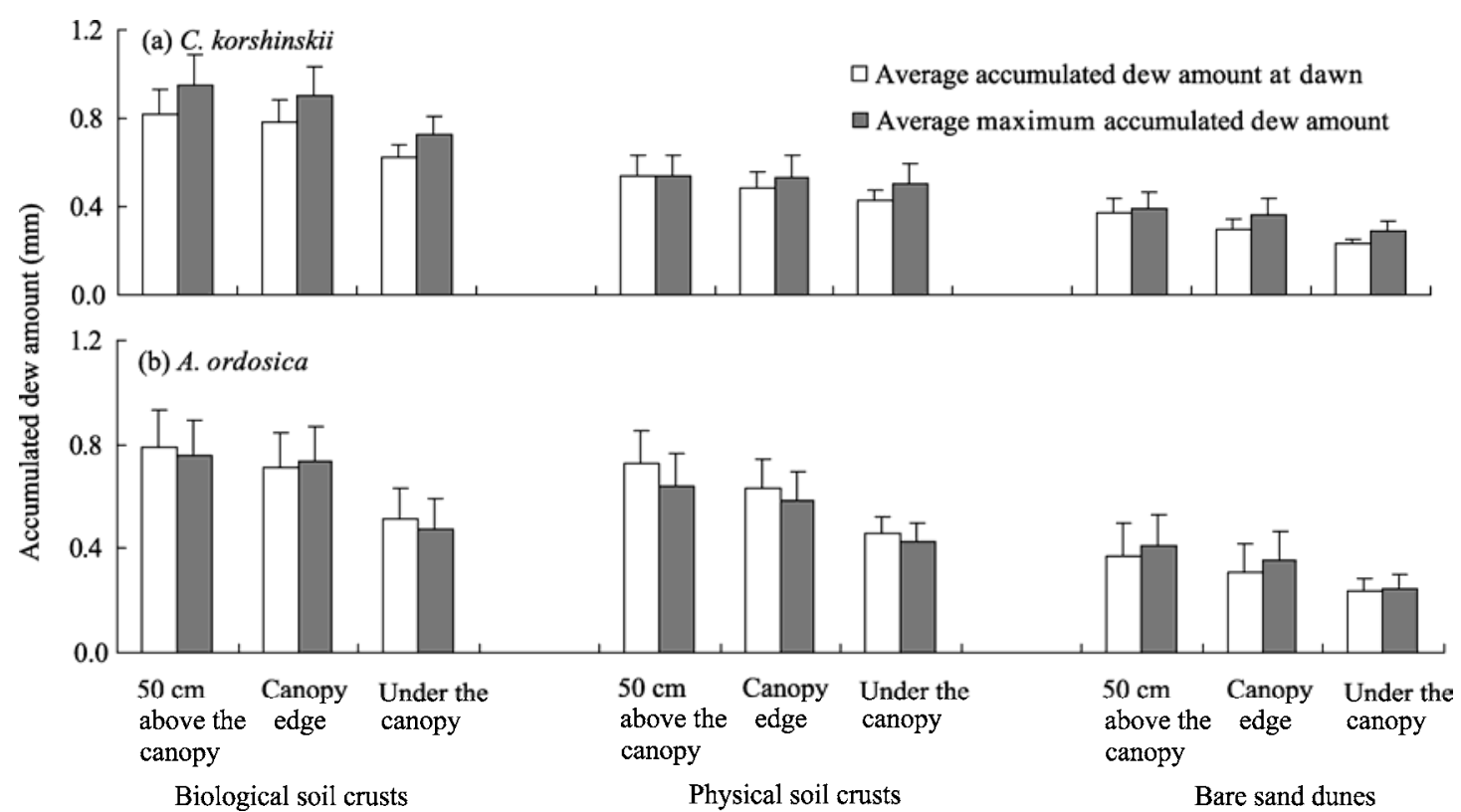

Fig. 5 Average accumulated dew amounts at dawn and average maximum accumulated dew amounts around the $C$. korshinskii (a) and A. ordosica (b) plants at different vertical heights on three kinds of soils. Bars represent one standard error, $n=8$.

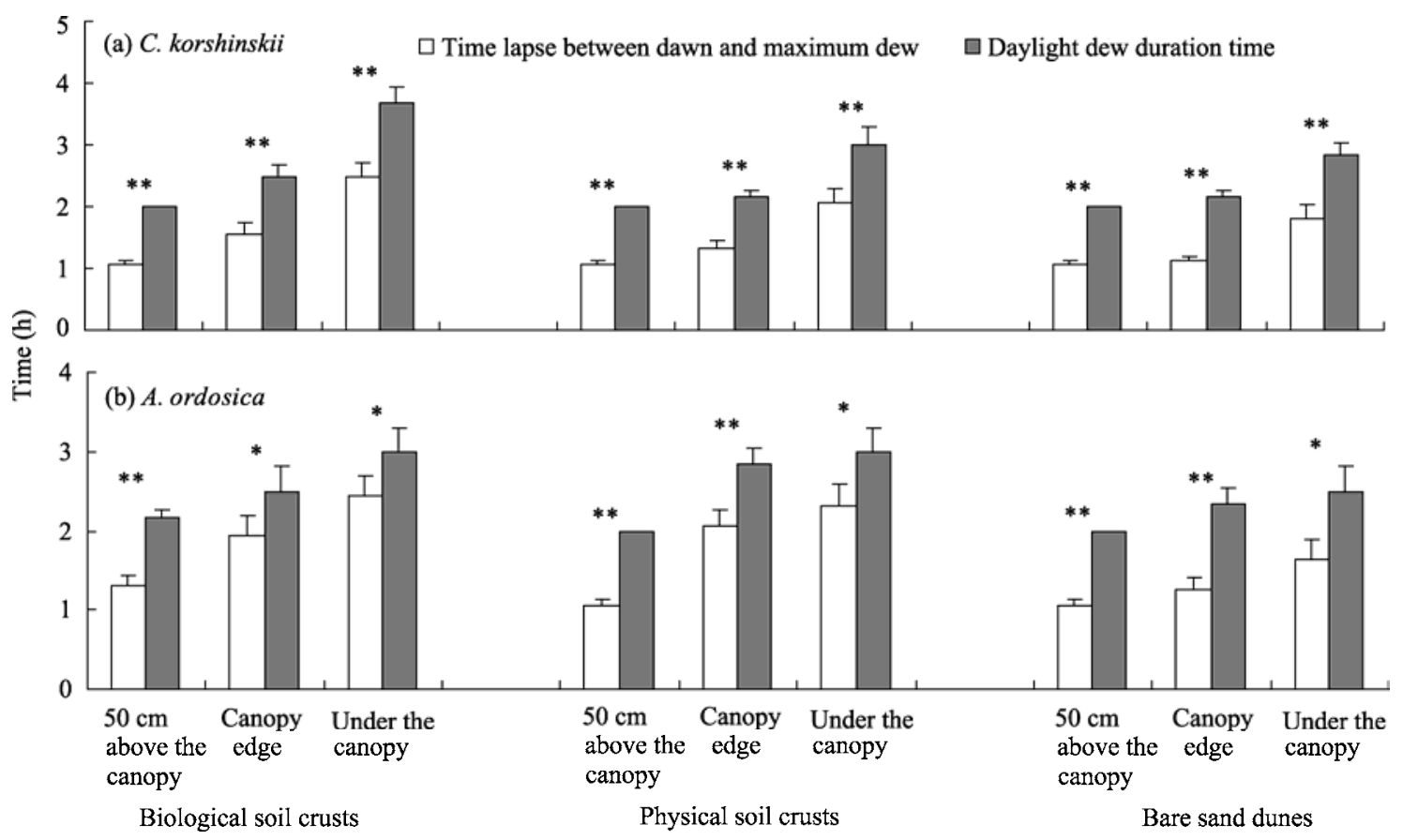

Fig. 6 Time lapses between dawn and maximum dew and the total daylight dew duration around the C. korshinskii (a) and A. ordosica (b) plants at different vertical heights on three kinds of soils. * and ** indicate significance at the 0.05 level and 0.01 level, respectively. Bars represent one standard error, $n=8$.

accounted for more than $50 \%$ of the daylight dew duration time for all observations at different microhabitats. Results of the time lapse between dawn and maximum dew and the daylight dew duration time indicated that the values were highest under the can- opy, followed by at the canopy edge, and then at 50 $\mathrm{cm}$ above the canopy. The proportion of the time lapse from dawn to maximum dew accounting for the daylight dew duration time was higher close to the soil surface, indicating that dew still formed after sunrise 
given the comprehensive effect of weather conditions and environmental factors. The extending time of dew duration may result from the shelter effects of the shrub stands.

\section{Discussion}

Generally, the environmental condition for moisture condensation occurrences was that when the soil surface temperature was lower than the air temperature and the relative humidity was nearly saturated. For the observation in the Shapotou area, although the relative humidity was lower, sometimes only $60 \%$, the increase of soil moisture content begun. This was induced by soil adsorption, a type of molecular condensation that results from the joint action of the molecular attraction of dry sand and the capillary condensation of a concave meniscus, a typical characteristic of dew formation in the steppe desert. The experiment was carried out during autumn when accumulated dew formation amounts were great, and the results indicated that the moisture adsorption and condensation amounts of sand can achieve more than the maximum hygroscopic moisture content (the maximum value is $0.45 \%$ in this area). They can also achieve more than the wilting moisture of plants, which is $0.6 \%$ in this area. The dune sand was nearly soaked by dew from 07:00 to 08:00 by visual observation, and the wetting depth was less than $1 \mathrm{~cm}$. The accumulated dew amounts on plant leaf surfaces were also great, and the glittering and translucent droplet on green leaves fell to the sand surface like rain due to the motion of the plants. Dew in the Shapotou area forms significant amounts of water for the physiological and ecological activities of plants, and it is an important factor for the carbon cycle in the desert ecosystem.

The diurnal variation characteristics of dew changed along with the variation of meteorological factors. Higher air relative humidity was the prerequisite of water vapour adsorption and condensation. Observations in the Shapotou area showed that $60 \%$ was the lowest value of relative humidity for water vapour adsorption and condensation in artificially revegetated desert area, but the evaporation was primarily below this value. The air temperature and net radiation were also important factors influencing water vapour adsorption and condensation, and both indicated opposite diurnal variation characteristics com- pared to the relative humidity. The effect of wind on dew formation was complex, and its effect was not significant due to the weakened wind force during the observation period. Microhabitats formed by the shrub stands changed the dew formation characteristics, delayed the arrival time of the maximum accumulated dew amounts and extended the dew duration under the canopy. The influence was more significant under the more dense shrub stands, and the effect of thick living plants was more significant than that of dead plants. The different soil surface moisture conditions under different microhabitats may be one of the main factors influencing the variations of accumulated dew amounts. Soil moisture at 5-cm depth for different microhabitats during the measurement period indicated that the values were in the order of L.C.>L.A.>D.C.>I.C.>bare sand dunes. At first, higher soil moisture under the shrub stands enabled the adsorption of moisture, then, the heat capacity of water was higher. In contrast with the water vapour condensation on the soil surface, the higher soil moisture under the shrub stands induced the decrease of soil temperature quite slowly at night. Moreover, compared with the dew formation, the difference of daily air temperature under the canopy was less. Previous research (Lloyd, 1961) on the effect of vegetation on dew formation indicated that the vegetation hindered the formation of dew under the canopy, so most dew formed on the plant surface and the accumulated dew amounts on the soil surface decreased. At the same time, microhabitats formed by tall plants hindered soil adsorption and condensation. Plant species and growth stage influenced dew formation amounts (Xiao et al., 2009). Plant leaf characteristics also influenced dew formation amounts, and the dew amounts were higher on horizontal leaves than on vertical leaves (Sudmeyer et al., 1994).

Shrub stands influenced the vertical distribution characteristics of dew. The dew distribution was uneven within the shrub stands, changing along with the variations of meteorological conditions and leaf distribution and structure (Jacobs and Nieveen, 1995). Our results indicated that the accumulated dew formation amount was greater at $50 \mathrm{~cm}$ above the canopy while the dew duration was longer under the canopy, which were consistent with the results of Barradas and Glez-Medellín (1999) and Jacobs et al. (2005). Jacobs 
et al. (1994) indicated that the dew duration at different layers were the same within canopy in a corn field. Cooling was the main way to induce the saturation of water vapour, which could promote condensation. Some water escaped from the plants during respiration and weaker evaporation at night, increasing the relative humidity around the shrub stands. Air temperature was lower in the upper air than in the soil surface, and water vapour condensed above the canopy at first, resulting in greater accumulated dew amount at higher positions. The dry process also appeared above the canopy at first due to solar radiation after sunrise and wind force. The shelter of the canopy induced longer wetting duration under the canopy, and the droplets dripping from leaves and overflow water from stems also accumulated under the canopy and increased the duration of moisture there.

\section{Conclusions}

Dew formation is influenced by plant species and microhabitats in arid desert ecosystems. Compared to the nearby open space, the surface soil moisture increased, the range of daily air temperature decreased, and a series of meteorological conditions changed under the shrub stands. Together with the blocking effect of the shrub stands itself, the beginning time of dew formation delayed and the accumulated dew amount decreased under the canopy. The condensation process began 2 hours earlier and the accumulated formation amount was nearly 4 times more under bare sand dunes than under L.C. When the shrub canopy became denser, the accumulated dew amount decreased. The maximum accumulated dew amounts were 0.35 and $0.6 \mathrm{~mm}$ for L.C. and L.A., respectively. On the other hand, the loss of dew after sunrise was slower due to the shading effects of the shrub stands, and the residence time of dew on soil surface extended accordingly. The shrub stands also influenced the vertical distribution of dew. The condensation process and the beginning time of dew formation occurred earlier above the canopy compared to under the canopy. The accumulated dew formation amounts decreased gradually along the gradient from above to below the shrub stands. The daily dew duration increased more significantly under the canopy than above the canopy after sunrise due to the slower evaporation process.

\section{Acknowledgements}

This research was financially supported by the National Natural Science Foundation of China (41201085) and the 100 Talents Program of the Chinese Academy of Sciences. We appreciate two anonymous reviewers for their helpful comments and suggestions. We are also very grateful to Dr. Ronny BERNDTSSON for his careful reading and correction of the manuscript.

\section{References}

Agam N, Berliner P R. 2002. The role of dew in the water and heat balance of bare loess soil in the Negev Desert: quantifying the actual dew deposition on the soil surface. Atmosphere Research, 64(1-4): 323-334.

Agam N, Berliner P R. 2006. Dew formation and water-vapour adsorption in semiarid environments: a review. Journal of Arid Environments, 65: 572-590.

Barradas V L, Glez-Medellin M G. 1999. Dew and its effect on two heliophile understorey species of a tropical dry deciduous forest in Mexico. International Journal of Biometeorology, 43: 1-7.

Bourque C P A, Arp P A. 1994. Dawn-to-dusk evolution of air turbulence, temperature and sensible and latent heat fluxes above a forest canopy: concepts, model and field comparisons. Atmosphere-Ocean, 32(2): 299-334.

Breshears D D, McDowell N G, Goddard K L, et al. 2008. Foliar absorption of intercepted rainfall improves woody plant water status most during drought. Ecology, 89(1): 41-47.

Brown R, Mills A J, Jack C. 2008. Non-rainfall moisture inputs in the Knersvlakte: methodology and preliminary findings. Water SA, 34: 275-278.

Del-Val E, Armesto J J, Barbosa O, et al. 2006. Rain forest islands in the Chilean semi-arid region: fog-dependency, ecosystem persistence and tree regeneration. Ecosystems, 9: 598-608.

Gouvra E, Grammatikopoulos G. 2003. Beneficial effects of direct foliar water uptake on shoot water potential of five chasmophytes. Canadian Journal of Botany, 81(12): 1278-1284.

Hao X M, Li C, Guo B, et al. 2012. Dew formation and its long-term trend in a desert riparian forest ecosystem on the eastern edge of the Taklimakan Desert in China. Journal of Hydrology, 472-473: 90-98.

Jacobs A F G, van Pul A, El-Kilani R M M. 1994. Dew formation and the drying process within a maize canopy. Boundary-Layer Meteorology, 69: 367-378.

Jacobs A F G, Nieveen J P. 1995. Formation of dew and the drying process within crop canopies. Meteorological Applications, 2: 249-256.

Jacobs A F G, van Boxel J H, Nieveen J. 1996. Nighttime exchange processes near the soil surface of a maize canopy. Agricultural and Forest Meteorology, 82(1-4): 155-169.

Jacobs A F G, Heusinkveld B G, Berkowicz S M. 2000. Dew measurements along a longitudinal sand dune transect, Negev Desert, Israel. International Journal of Biometeorology, 43(4): 184-190.

Jacobs A F G, Heusinkveld B G, Klok E J. 2005. Leaf wetness within a lily canopy. Meteorological Applications, 12: 193-198.

Kidron G J. 2005. Angle and aspect dependent dew and fog precipitation in the Negev desert. Journal of Hydrology, 301: 66-74. 
Kosmas C, Danalatos N G, Poesen J, et al. 1998. The effect of water vapour adsorption on soil moisture content under Mediterranean climatic conditions. Agricultural Water Management, 36: 157-168.

Lekouch I, Muselli M, Kabbachi B, et al. 2011. Dew, fog, and rain as supplementary sources of water in south-western Morocco. Energy, 36(4): 2257-2265.

Li X R, Kong D S, Tan H J, et al. 2007. Changes in soil and vegetation following stabilization of dunes in the southeastern fringe of the Tengger Desert, China. Plant and Soil, 300: 221-231.

Li X Y. 2002. Effects of gravel and sand mulches on dew deposition in the semiarid region of China. Journal of Hydrology, 260: 151-160.

Lloyd M G. 1961. The contribution of dew to the summer water budget of northern Idaho. Bulletin of the American Meteorological Society, 42: $572-580$.

Mao W, Zhang T H, Li Y L, et al. 2012. Allometric response of perennial Pennisetum centrasiaticum Tzvel to nutrient and water limitation in the Horqin Sand Land of China. Journal of Arid Land, 4(2): 161-170.

Martin C E, Willert D J. 2000. Leaf epidermal hydathodes and the ecophysiological consequences of foliar water uptake in species of Crassula from the Namib Desert in southern Africa. Plant Biology, 2(2): 229-242.

Moffett M W. 1985. An Indian ant's novel method for obtaining water. National Geographic Research, 1(1): 146-149.

Pan Y X, Wang X P. 2009. Factors controlling the spatial variability of surface soil moisture within revegetated-stabilized desert ecosystems of the Tengger Desert, Northern China. Hydrological Processes, 23(11): 1591-1601.

Pan Y X, Wang X P, Zhang Y F. 2010. Dew formation characteristics in a revegetation-stabilized desert ecosystem in Shapotou area, Northern China. Journal of Hydrology, 387: 265-272.
Pitacco A, Gallinaro N, Giulivo C. 1992. Evaluation of actual evapotranspiration of a Quercus ilex L. stand by the Bowen Ratio-Energy Budget method. Vegetation, 99-100: 163-168.

Shachak M, Leeper A, Degen A A. 2002. Effect of population density on water influx and distribution in the desert snail Trochoidea seetzenii. Ecoscience, 9: 287-292.

Shapotou Desert Experimental Research Station, Chinese Academy of Sciences. 1991. Study on Shifting Sand Control in Shapotou Region of the Tengger Desert (2). Yinchuan: Ningxia People’s Publishing House, 101-119.

Simonin K A, Santiago L S, Dawson T E. 2009. Fog interception by Sequoia sempervirens (D. Don) crowns decouples physiology from soil water deficit. Plant, Cell \& Environment, 32(7): 882-892.

Sudmayer R A, Nulsen R A, Scott W D. 1994. Measured dewfall and potential condensation on grazed pasture in the Collie River basin, southwestern Australia. Journal of Hydrology, 154: 255-269.

Wang S, Zhang Q. 2011. Atmospheric physical characteristics of dew formation in a semi-arid loess plateau. Acta Physica Sinica, 60(5): 059203.

Xiao H, Meissner R, Seeger J, et al. 2009. Effect of vegetation type and growth stage on dewfall, determined with high precision weighing lysimeters at a site in northern Germany. Journal of Hydrology, 377: 43-49.

Ye Y H, Zhou K, Song L Y, et al. 2007. Dew amounts and its correlations with meteorological factors in urban landscapes of Guangzhou, China. Atmosphere Research, 86(1): 21-29.

Zheng X J, Song L, Yan L. 2011. Leaf water uptake strategy of desert plants in the Junggar Basin, China. Chinese Journal of Plant Ecology, 35(9): 893-905.

Zhuang Y L, Ratcliffe S. 2012. Relationship between dew presence and Bassia dasyphylla plant growth. Journal of Arid Land, 4(1): 11-18. 